\title{
Towards the Realization of an ICT Education Living Lab - The TechTeachers.co.za Success Story
}

\author{
Albertus A. K. Buitendag and Frederik G. Hattingh, \\ Tshwane University of Technology \\ Pretoria, Tshwane, South Africa \\ buitendagAAK@tut.ac.za hattinghFG@tut.ac.za \\ Matthew Hains \\ Woodlands International College \\ Boksburg, South Africa \\ matt@techteachers.co.za
}

\begin{abstract}
This paper presents the success story of the intuitive vision of an Information and Communication Technology (ICT) high school educator in South Africa. The growth and evolution of a Community of Practice towards a full-fledged living lab is investigated. A grounded theory study analyses the living lab concept and highlights some of the current challenges secondary high school ICT education face within the South African educational landscape. Some of the concepts, ideas, best practices, and lessons learned in the establishment and running of two web based technologies to support secondary school ICT subjects is discussed. The researchers present a motivation for the use of living labs to address some of the issues identified and highlights how the existing platforms fits into bigger design.
\end{abstract}

Keywords: Collaboration, Community of Practice, ICT Education, Living Labs, TechTeachers

\section{Introduction}

ICT related education in South Africa underwent various changes in its long history as part of the South African secondary school curriculum. This willingness to renew and change was evident as the South African Department of Basic education recently embarked on a re-circulation process for all school curricula (de Jager, 2011). The current South African ICT curriculum consists of two subjects, namely, Computer Applications Technology (CAT) and Information Technology (IT). Africa in general and South Africa specifically face a myriad of challenges within the educational sector (Teferra \& Altbachl, 2004; Welch, 2002). The country is continuously seeking and new and innovative ways of providing solutions to educational communities (Ford \& Leinonen, 2009). Over recent years the Living

Material published as part of this publication, either on-line or in print, is copyrighted by the Informing Science Institute. Permission to make digital or paper copy of part or all of these works for personal or classroom use is granted without fee provided that the copies are not made or distributed for profit or commercial advantage AND that copies 1) bear this notice in full and 2) give the full citation on the first page. It is permissible to abstract these works so long as credit is given. To copy in all other cases or to republish or to post on a server or to redistribute to lists requires specific permission and payment of a fee. Contact Publisher@InformingScience.org to request redistribution permission.
Lab concept and the adoption of living labs has grown globally with similar interests in Southern Africa and Africa. One approach supported by the researchers and proven in practice is the establishment and creation of Living Labs to support community oriented activities, which include education (cf. Avellis, Agrimi, Di Ciano, Grasso, \& Surico, 2015; Buitendag, Wassermann \& Pretorius, 2013) 


\section{The Subjects CAT and IT}

CAT and IT are two elective FET school subjects which form part of the FET phase of the South African secondary school curriculum. Each subject in the South African curriculum is described in an official policy document called 'The Curriculum and Assessment Policy Statement (CAPS)' (DoE, n.d.). The CAPS for CAT describes the subject as follows: "Computer Applications Technology is the study of the integrated components of a computer system (hardware and software) and the practical techniques for their efficient use and application to solve everyday problems. The solutions to problems are designed, managed and processed via end-user applications and communicated using appropriate information and communication technologies (ICTs). ICTs are the combination of networks, hardware and software as well as the means of communication, collaboration and engagement that enable the processing, management and exchange of data, information and knowledge" (DoE, 2010a).

IT is described as "Information Technology is the study of the various interrelated physical and nonphysical technologies used for the capturing of data, the processing of data into useful information and the management, presentation and dissemination of data. Information Technology studies the activities that deal with the solution of problems through logical and computational thinking. It includes the physical and non-physical components for the electronic transmission, access, and manipulation of data and information" (DoE, 2010b).

Each of the two subjects stresses and promotes the application of logical thinking as well as computational thinking in the development of solutions for everyday problems in real world environments. The subject CAT focuses on the creation of solutions which are designed, managed, and processed via enduser applications. The subject IT promotes the use of a programming language and subsequent programming constructs in the development of solutions utilizing a high level programming language, i.e., Delphi or Java.

\section{CAT and IT Teacher Support}

Each provincial education department employs subject advisors whose primary task is to support the various educators in an applicable district with subject related matters. The subject advisors are supposed to help with the knowledge support requirements of the individual educator as required (Legotlo et al., 2002, p. 117). In addition, subject advisors are also tasked with providing some content specific training, and advice on best practices. Depending on the education domain this is often not the case, and many advisors face an array of problems and challenges which are often in line with that of the teachers. This fact is often stressed on forums and open communities and workshops.

\section{The TechTeachers CoP - Background and History}

The TechTeachers Facebook page and the later accompanying TechTeachers.co.za site started off as an idea from a young ICT educator new to the CAT subject in 2011. One of the problems experienced by the educator was that, besides the official textbook, there were limited resources that could be consulted for help. Being the only educator teaching the subject at the school there were no peers or other colleagues to reach out to for help.

There was little or limited examples of assessments and tutorials except for the ones made available by textbook publishers. In an attempt to address some of these needs a Facebook group was established in early 2012. Early on the Facebook group included teachers from schools in surrounding areas.

The main aim of the group was to connect educators and allow for the exchange of ideas, knowledge, teaching materials, and assessments. The group grew in members and rapidly became a popular community of practice.

According to Wenger (2006) communities of practice (CoP) are groups of people who share a concern or a passion for something they do and learn how to do it better as they interact regularly with one an- 
other. A CoP is often categorized as people who engage in a process of collective learning in a shared domain of human endeavor. Serrat (2008) stresses that "communities of practice are groups of likeminded, interacting people who filter, amplify, invest and provide, convene, build, and learn and facilitate to ensure more effective creation and sharing of knowledge in their domain."

One of the important practices of a CoP according to Serrat (2008) is to establish means and a platform to exchange data, information, and knowledge freely. Within the TechTeachers domain and group the practice of information and knowledge sharing became prevalent, and soon a newer approach was required to host and share resources, this lead to the establishment of the TechTeachers.co.za site.

As of Nov 2014 there are more than 750 active members on the TechTeachers.co.za site, and in February 2015 the number grew to almost 800 active members. The companion FB group has over 400 members. Members hail from across South Africa representing all nine provinces.

\section{Research Question, Method, and Problem}

Both the TechTeachers.co.za website and related Facebook group have a large number of participants. With only one administrator, who is also a full time educator, the task of managing and maintaining the two interrelated sites is ever increasing and a daunting challenge. It is the researchers' goal to find an approach that will address this issue but also to align the objectives and aims with evidence from research.

The main research question presented is: How could the website and the Facebook page be incorporated as part of a Living Lab environment and its operations?

In order to address the main research question the researchers followed the suggestion of Van der Walt, Buitendag, Zaaiman, and van Vuuren (2009) to apply systems thinking and thinking patterns in the process of designing and constructing a living lab. Systems thinking are described by Senge (1990) as "a discipline for seeing wholes. It is a framework for seeing interrelationships rather than things, for seeing patterns of change rather than static "snapshots"'. Today systems thinking is needed more than ever because we are becoming overwhelmed by complexity. On the ability of systems thinking to aid in the identification of problems by focusing on systematic structures as a whole Neill (n.d.) explains that the structures itself presents the greatest leverage for problem solving, which could be addressed with a range of different tools.

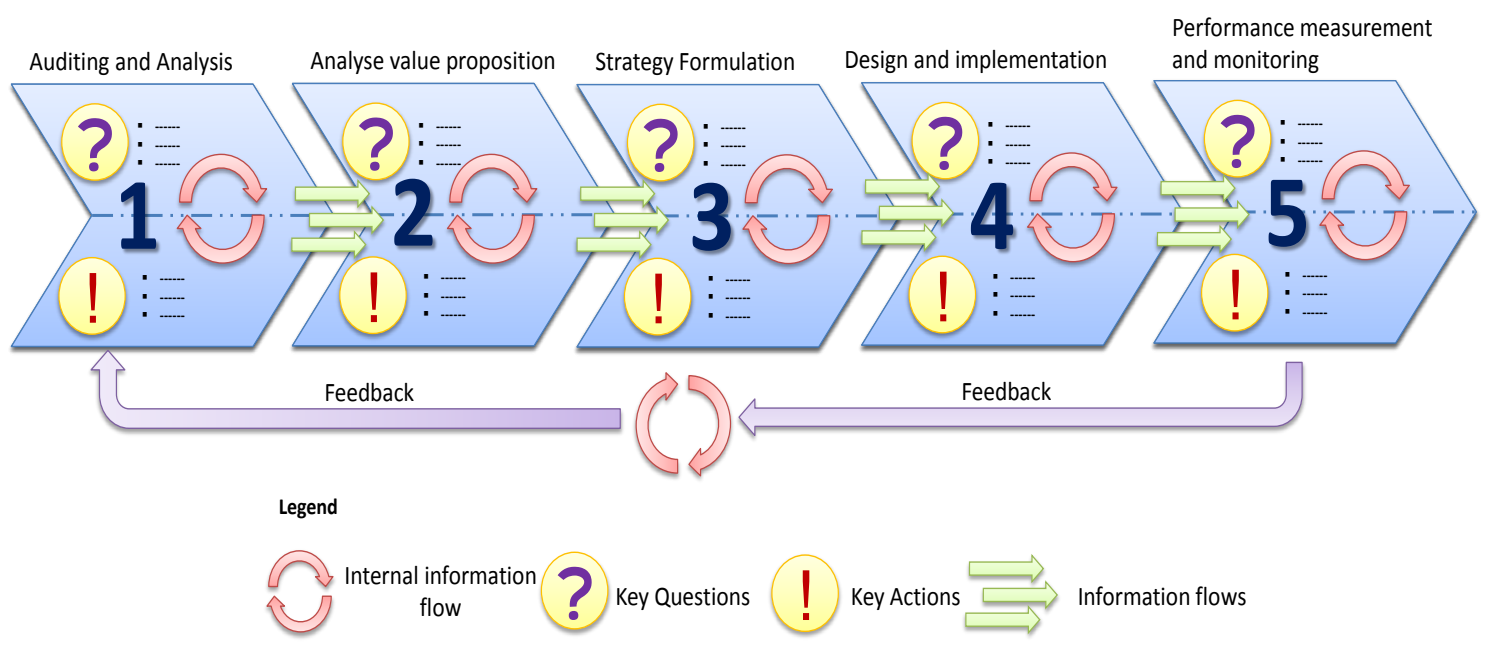

Figure 1: Five phase development modal 
Figure 1 presents the a five phase model that highlights steps in the thinking and design processes which contribute towards to possible development of a tool or, in the case of this research, a Living Lab (LL) which are supported by the application of thinking patterns. As part of the research process into the evolution of the two web based sites towards a LL each of the phases was applied. Each of the phases presented in the model entail the following:

1. Auditing and analysis of the current tools and solution, by identifying the key issues connected to the problem at hand. The analysis also helps in the identification of the role players to create suitable partnerships for collaboration where needed. A deep understanding of the problems, its drivers and the environment are required in order to respond to the needs and to allow for the correct information flow to the next phase.

2. Analysis of the current value proposition, by brainstorming all value chains (primary and support activities) connected to the component or solution at hand.

3. Identification of suitable strategies to create and design the component or solution.

4. Design and implementation of the solution based on the strategies identified in the prior phase Create and implement the strategies.

5. Performance measurement and monitoring of the tool or solution by constant evaluation based on feedback.

Each of the various phases are driven by the application of thinking patterns (system, process, value, critical, analytical, etc.), based on simple questions, for example:

- What? (Governance mechanisms, value network, processing operations)

- Why? (Objectives)

- Where? Who? How? (Enable)

Each of the questions allows for key actions to be taken and the subsequent results flow into the next phase to enable the process. In order to realize the first two phases of the model and to identify the real issues and problems at hand, a grounded theory (GT) study was conducted. GT is described by Scott (2009) as a research method that will "enable a researcher to develop a theory which, allow the researcher to offer an explanation about the main concern of the population of your substantive area and how that concern is to be resolved or how it could be presented". GT was selected as a method for research as part of this study due to the notion that the method often starts with a research situation which require the researchers to gain a better understanding of what is really happening and how the various stakeholders and role-players manage their situations and roles (Dick as cited by Ausband, 2006).

The research situation in this study refer to the current state of Secondary ICT education in South Afri$\mathrm{ca}$, and the role players include educators, subject advisors, and the broader education community as a whole. The GT study approach was used in order to guide the first three phases of the development model presented in Figure 1.

\section{Grounded Theory Study}

As part of a grounded theory study the application of the dictum that "all is data" from Glaser (2007) was applied. Data from various sources, such as e-mail conversations, suggestions and minutes, and notes from regional and provincial subject meetings, were used as part of the GT method coding process (Brown, Gordon, Janik, \& Meyer, 2005; Esteves, Ramos, \& Carvalho, 2002).

Data spanning over 10 years were used as part of this study. The initial coding process also included posts to community mailing lists archives such as the closed Comp studies mailing list in SA for CAT 
and IT (Comp-Studies, 2014). Other sources of data included notes and presentations used as part of many workshops on regional, provincial, and national levels. At these workshops teachers and subject advisors often discussed various problems and issues. The final themes, codes and categories identified as part of the grounded theory study is presented as key issues and challenges as depicted in Figure 2.

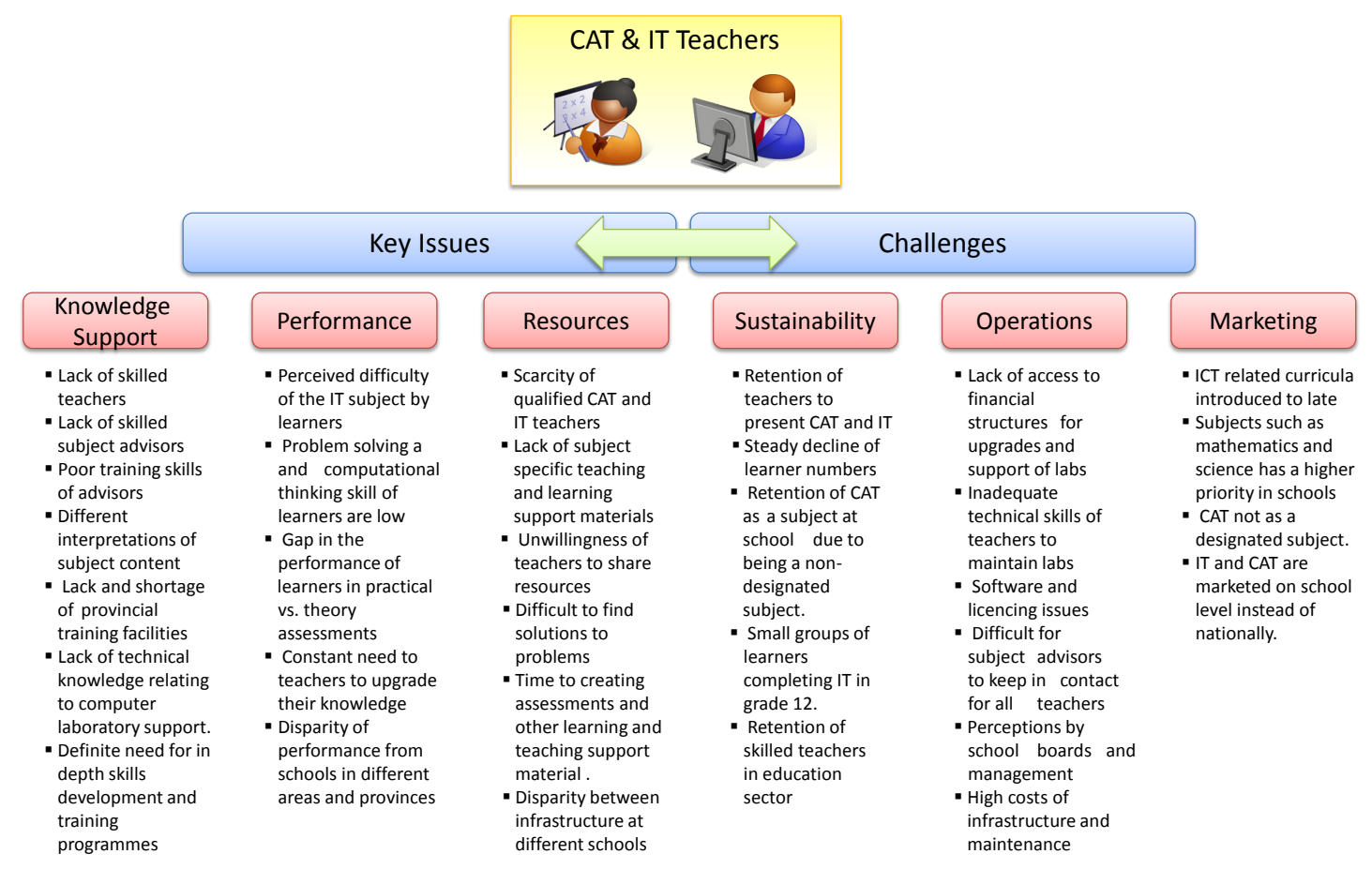

Figure 2: Key issues and challenges CAT and IT teachers face

Various key issues and challenges presented themselves as categories and themes as depicted as part of Figure 2. Many of these categories evolve around issues and challenges pertaining to knowledge support and resources. Some of these challenges are elaborated next.

Many provinces and districts have a shortage of skilled and trained teachers, as many teachers trained for other disciplines, e.g., Mathematics and Science are often used to present the subjects CAT and/or IT. This is also true for provincial subject advisors as many are also inadequately trained and are sometimes from other subject domains. Subject advisors with a CAT background are also appointed as subject advisors for IT.

The subject content for CAT is broad and some teachers lack the skills in specific advanced areas of the curriculum. In IT educators often lack deep knowledge of advanced programming related concepts such as Object-Oriented Programming. Difficulties are often experienced by advisors and teachers to keep abreast with new advancements in programming and related technology due to a comprehensive curriculum.

Provinces lack adequately equipped training infrastructure and support for laboratories at existing facilities, which is often the case with schools as well. One major challenge is that ICT integration in lower grade subjects is also non-existent, with some ICT-related curriculum only being presented at more affluent schools.

One of the major broad resource issues highlighted is the fact that teachers, schools, and districts as well as provinces often work in silos and are reluctant to share resources due to factors that include, amongst others, fear of criticism and a perception of share with no return. The perception of share with 
no return entails a general feeling that time and effort spent in the development of materials are often not equally rewarded with the resources offered in return.

Some other resource and knowledge support problems include:

- Time and resource intensive practice of creating tutorials and assessments.

- Often a lack of small outcome specific tasks, exercises and tutorials.

- Shortage of content specific teaching and learning resource materials e.g. classroom posters etc.

One of the most detrimental consequences resulting from the issues and challenges mentioned is the fact that schools often decide to phase out CAT and IT as a subject in their schools.

\section{Presenting the Theory}

From the data that was analyzed and coded as part of the grounded theory process the core category emerged, which was saturated from the data, the codes, and the main categories. The core category presented itself as the lack of access to various resources and expertise and the sub categories as inadequate advisory and support services, operational difficulties, and skills development and training.

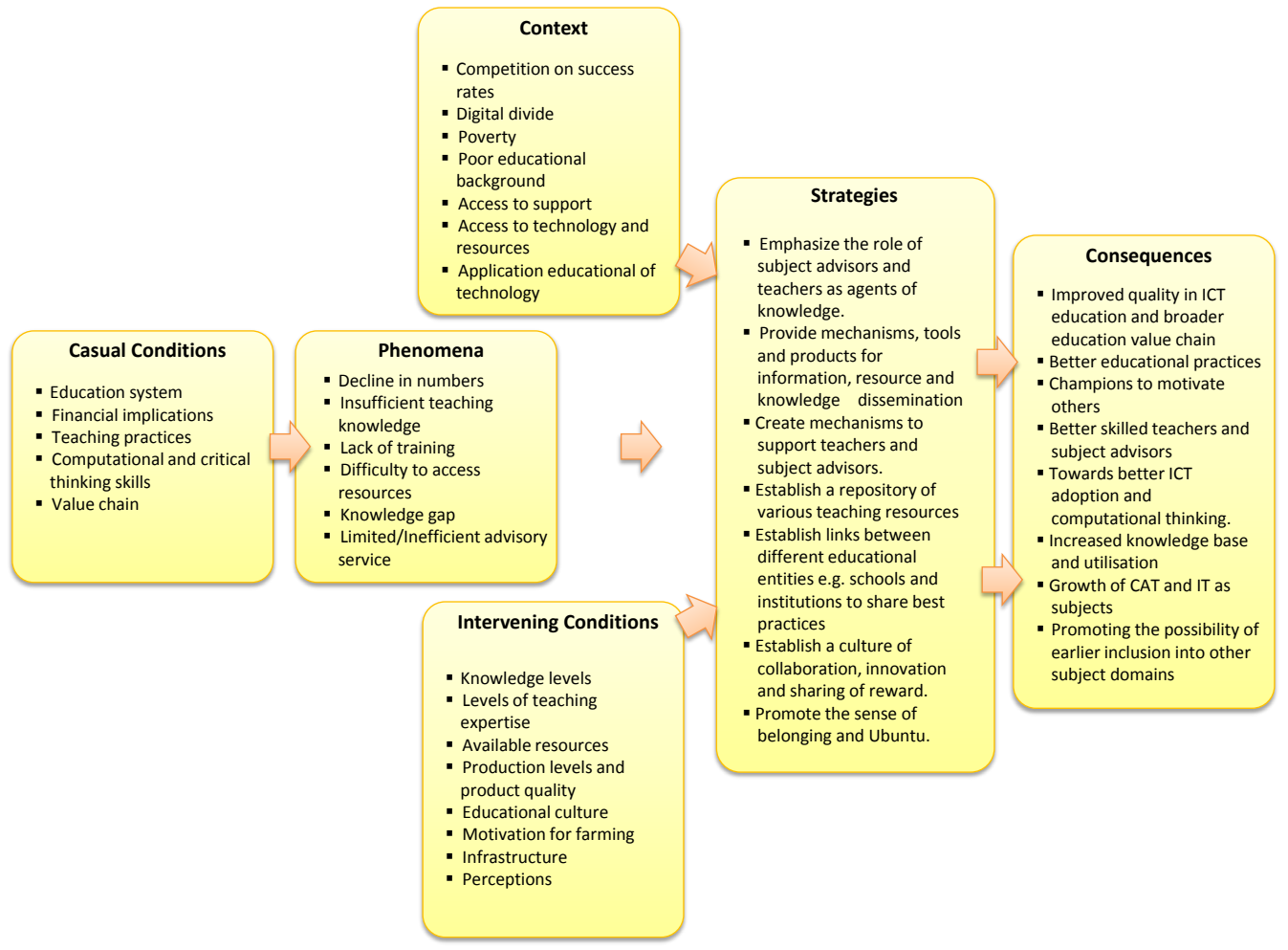

Figure 3: Theoretical model to address ICT related education needs

Figure 3, constructed by the researchers, is based on the sample provided by Creswell (2012, pp. 285380) and represent a theoretical model to address to core issues CAT and IT teachers as well as subject advisors face.

Figure 3 illuminates the fact that various casual conditions, such as problems within the secondary education system and the application of different teaching practices and financial resources, contribute towards the current phenomena which are experienced. Some of the phenomena include a decline in teacher and learner numbers, lack of adequate training and knowledge relating to the effective training 
of learners and teachers, as well as poor advisory services. The phenomena occur within the context of poverty barriers, poor educational background of various schools, and insufficient access to training and resources which include access to support. Various intervening conditions aid in the factoring and formulation of strategies, which include amongst others the establishment of mechanisms tools and products to support learning and teaching and the establishment of mechanisms to link various resources and experts. The predominant strategies lead to the perceived consequences of such an implementation.

The next section of this research motivates the use of a living lab approach to aid in the realization of the strategies in order to address the current phenomena, within the context of ICT related education and advisory services.

\section{TechTeachers Modeled as a Living Lab}

The modeling of the proposed solution presents the 4th phase of the development model as presented in Figure 1. One of the solutions to address the strategies and realize the perceived consequences is to establish an ICT education living lab, the modeling of which is based on the factory framework as presented by Buitendag, Hattingh, \& Van der Walt (2013) and Van der Walt et al. (2009).

The creation of solutions and tools to support ICT education presented as part of this paper requires a new way of thinking, not only because of the complexity but also due to the numbers of users involved with a substantial geographical span. One design and implementation solution strongly supported by the researchers is the Living Lab (LL) approach.

Pallot (2009, 2012) and Pallot, Alishevskikh, Pawar, Ruland, \& Prinz (2013) stresses the fact that living labs are to be regarded as user-centered open-innovation ecosystems integrating research and innovation within a Public-Private-People partnership through an iterative Experiential Design process, where the focus is placed on the quality of the user experience experimenting with a product or service and the capacity of the living lab to capture the previous development and design experiences in the form of experiential knowledge.

For the purpose of this research a living lab (LL) is regarded as a collaborative innovation environment that allows all stakeholders to partake in various innovative practices to enhance, to find solutions to shared problems, and to catalyze their current operations.

An important driver and consideration of a LL is the fact that end users are also seen as co-creators and co-designers of the products to be developed. In research presented by Lucassen, Klievink, \& Tavasszy (2014) it is stressed that "Living Lab frameworks should address the Lab environment with its stakeholders and their power relations and help to specify individual and common goals. It should help guide the participants in developing team spirit, having structured and at the same time spirited discussions without losing the final common goal. It helps to specify the requirements for the innovation, both on functional and technical level, and on both a short and longer term."

What differentiates the LL approach to other generic organizations resides in the fact that LL are driven, motivated, and evolve around a CoP. Where there is a strong focus on profit for sustainability in normal organizations, LL's on the other hand (with specific reference to Southern Africa) are often centered on innovation, co-creation, co-existence, and community advancement (Cunningham, Herselman, \& Cunningham, 2011; Følstad, 2008).

Figure 4 presents the LL factory framework on which the TechTeachers LL is to be based. 


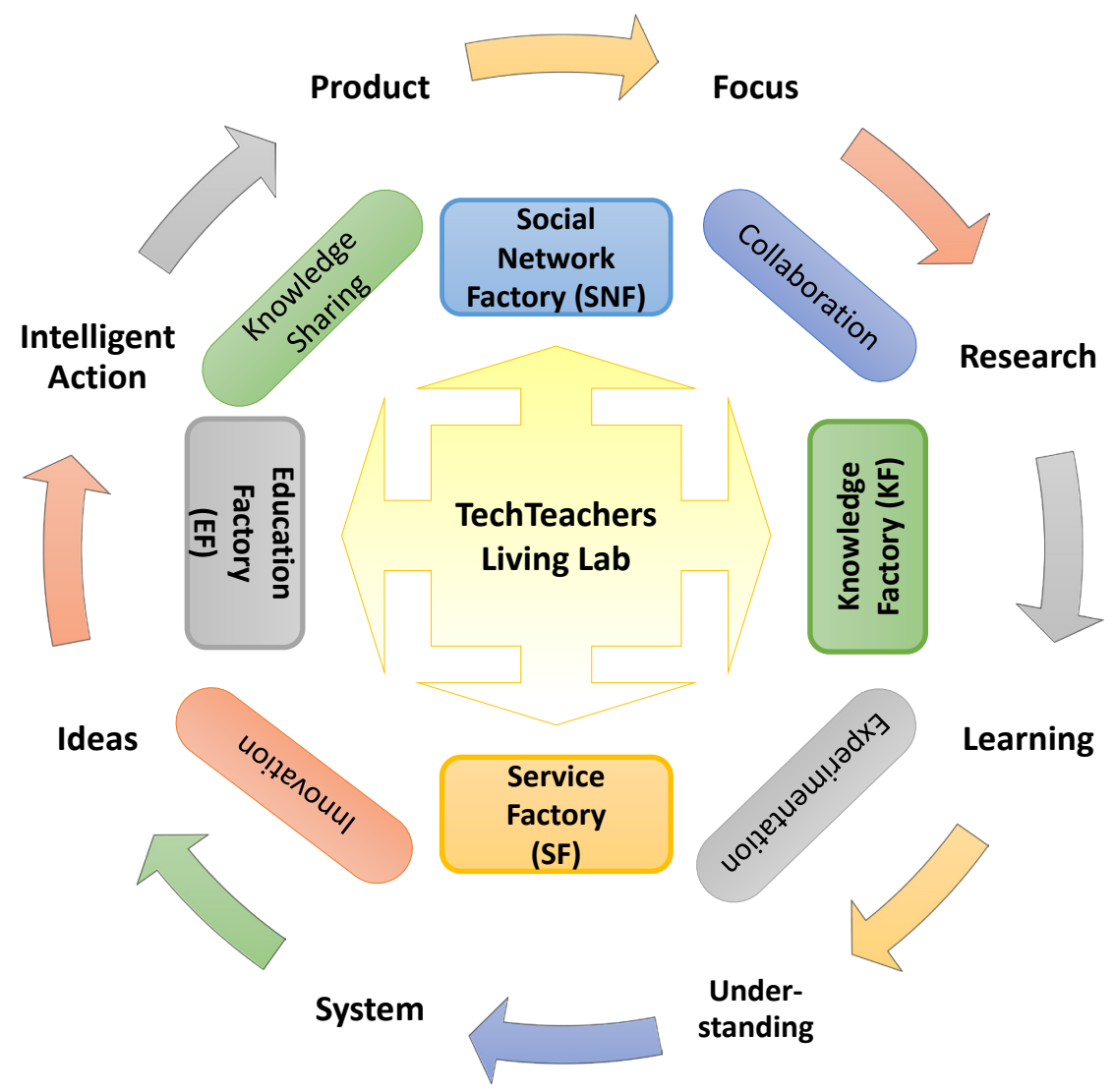

Figure 4: Educational ICT Living Lab Factory Framework

The reward of "Living Labbing" often encapsulates more than just the tangible or financial reward but promotes the uniquely African concept and philosophy of 'Ubuntu', a Zulu or Sotho aphorism which implies that "a person is a person through other persons," and in the contest of this research as "a teacher is teacher through other persons." Cilliers (2008) explains that "it is impossible to do the concept justice due to the richness of it within the African context," and points out that "it also underpins the concept of an open society." The concept of an open society is often linked to LL's which are often referred to as open living labs (c.f., European Network of Living Labs, 2012).

The framework as presented in Figure 4 incorporates the notions of Lucassen et al. (2014) by stressing the fact that participants work and collaborate towards a common goal and inherently should be allowed to have a platform for communication and debate that includes the sharing of knowledge and design experiences, i.e., experiential knowledge, and resources on various levels. The framework also incorporates the application of the various thinking strategies and practices of the phased development model to promote the creation of innovative solutions and products.

The LL is based on the virtual implementation of various factories, where each factory is regarded as a conceptual component with physical inputs, i.e., resources and a deliverable. The operations of the living lab are centered on a standard cyclic research process which confirm to the description of Ormrod and Leedy (2005).

The social network factory (SNF) is used for profiling and registration of community members, which predominantly includes teachers and subject advisors, and other members from related institutions, such as university staff and educational entities such as publishers. Social media tools, such as Facebook and Twitter, are utilized to facilitate and enable various functions such as dissemination of in- 
formation, gathering opinions and posting knowledge requests. One of the key components and enablers of the SNF is the CAT \& IT Teachers South Africa Closed Facebook group with 450 active members. One of the main purposes of the SNF is to enhance collaboration between members and the knowledge factory. Various tools utilized by groups and clusters of teachers include the use of Twitter to disseminate information and news, as well as WhatsApp for real-time communication.

The knowledge factory (KF) comprises various activities which promote different types of research utilizing different methodologies to enhance education practices. Research methods, such as prototyping, action research, grounded theory methods and experimentation, allow the participants to learn and gain a better understanding of their environment. Different types of knowledge in various forms are presented and managed as part of the KF of which examples include best practices, technical knowhow, advice, policies and procedures and other forms of informing, and knowledge objects. The KF also acts as a repository of teaching and learning objects and presents a platform for teachers to share and exchange and to gain new knowledge. One such example is the creation and maintenance of an integrated question bank, which could be used by teachers as part of their teaching and assessment practices.

The service factory (SF) presents the platforms for the creation of various tools and services based on the knowledge generated as part of the KF. Examples include different types of assessment, e.g., assignments, tests, and exams, as well as model solutions and memorandums or tools to enhance education, such as software packages to manage assessment marks and the monitoring of student activity in a lab, video's, or class room posters. These tools often allow for the application of innovative teaching practices and generally drive innovation as part of the system.

The education factory (EF) acts as the test bed for the various tools and services developed as part of the SF, of which most are developed by the LL members themselves. The use of these tools and services could lead to new ideas and intelligent action taken by members, which could result in a new product and focus for the group. The delivered product to the community, i.e. NF, is often the instigator for new research and discussion, which could lead to a new focus. Examples of such instances could be the implementation of a new method for assessing a specific learning outcome of the curriculum or a revolutionary method of transferring knowledge.

\section{TechTeachers Facebook Page}

The TechTeachers Facebook (FB) page was initially started as a communication platform for a small group of teachers in the same geographical area. The current popularity of the FB group is evident in the number of posts and 439 active users as of November 2014. The description and existence of the group is presented as "for teachers and educational professionals only, specifically CAT (Computer Applications Technology) and IT teachers in South Africa. The group's purpose is for teachers to support each other with content, advice and communication. The group allows members to share experiences, advice, resources and materials. Teachers from all schools, government/private, English, Afrikaans etc. are welcome provided they are CAT, IT or computer literacy teachers" (cf., www.facebook.com/groups/cat.teachers ).

As part of this study the FB group is regarded as an ideal platform to realize the SNF of the LL framework presented in Figure 4 and enable the various objectives of the SNF. An analysis of the use of the FB group based on 200 consecutive postings not including replies or comments reveal some interesting observations, as presented in Table 1. 
Table 1: TechTeachers FB group post analysis

\begin{tabular}{|c|c|c|c|}
\hline Posting Type & Description & $\begin{array}{l}\text { Nr of posts } \\
\text { (out of 200) }\end{array}$ & $\%$ \\
\hline Announcement & Short announcement or post pertaining to an activity observation or general concept. & 15 & 7.5 \\
\hline $\begin{array}{l}\text { Humor / Motivational } \\
\text { statement }\end{array}$ & $\begin{array}{l}\text { Cartoon, illustration, joke or motivational statement. Examples include answers of a humoristic } \\
\text { nature and postings encouraging fellow members in activities such as evaluating assessments. }\end{array}$ & 19 & 9.5 \\
\hline $\begin{array}{l}\text { Single question or simple } \\
\text { request for knowledge }\end{array}$ & $\begin{array}{l}\text { Simple questions and requests for information and knowledge which include technical know } \\
\text { how, content and curriculum issues. }\end{array}$ & 36 & 18 \\
\hline Quick fact or link & $\begin{array}{l}\text { Links to interesting articles and other sources or a quick fact pertaining to subject related } \\
\text { content. }\end{array}$ & 39 & 19 \\
\hline $\begin{array}{l}\text { More detailed knowledge } \\
\text { request, survey or poll. }\end{array}$ & $\begin{array}{l}\text { Knowledge requests which require more detailed solutions or requests relating to the } \\
\text { completion or a survey or contributing to a poll. }\end{array}$ & 8 & 4 \\
\hline $\begin{array}{l}\text { Posting relating to an } \\
\text { educational resource, } \\
\text { knowledge, research or } \\
\text { activity }\end{array}$ & $\begin{array}{l}\text { Postings which presents, an activity towards one of the learning outcomes of the curriculum or } \\
\text { an activity to reinforce a concept or explanation thereof. Also include postings to the results of } \\
\text { research }\end{array}$ & 4 & 2 \\
\hline $\begin{array}{l}\text { New resource to support the } \\
\text { curriculum }\end{array}$ & $\begin{array}{l}\text { Postings relating to new materials, including exercises, tutorials, notes, videos, articles or } \\
\text { assessments. }\end{array}$ & 22 & 11 \\
\hline Policy or governance issue & $\begin{array}{l}\text { Relating to educational departments, policy and procedures and curriculum issues, which } \\
\text { include directives. }\end{array}$ & 4 & 2 \\
\hline Job opportunities, vacancies & Relating to new vacancies at schools and opportunities for teaching & 10 & 5 \\
\hline $\begin{array}{l}\text { New resource, research or } \\
\text { knowledge }\end{array}$ & Posting relating to a new research within the ICT field & 17 & 8.5 \\
\hline $\begin{array}{l}\text { Collaboration activity or } \\
\text { request for participation }\end{array}$ & $\begin{array}{l}\text { Request for fellow members to become part of an activity such as developing teaching materials, } \\
\text { assessments and other resources }\end{array}$ & 6 & 3 \\
\hline $\begin{array}{l}\text { Notifications of events, } \\
\text { workshops and training } \\
\text { opportunities }\end{array}$ & General postings on courses, ICT school and district based events such as Olympiads and expos. & 8 & 4 \\
\hline General comments & $\begin{array}{l}\text { Postings relating to general comments applicable to the group or comments from fellow } \\
\text { teachers }\end{array}$ & 13 & 6.5 \\
\hline
\end{tabular}

It is evident from the table that postings relating to knowledge requests and the sharing of knowledge are predominant. It is also evident that motivation plays an important role and that the FB group successfully acts as a platform for communication and promoting collaboration. Another indirect observation from reviewing the posts on the Facebook page is the speed in which responses to requests are given by fellow group members: $94 \%$ of all request related posts are presented with a solution, reference or link within 24 hours of the post being made. The 200 posts reviewed spanned over 45 days, which represents on average about 4 to 5 posts per day, excluding comments, responses, and likes.

\section{Techteachers.co.za}

The techteachers.co.za blog site (see Figure 5) was established out of a necessity to create a platform to host various shared resources and their descriptions. The TechTeachers.co.za blog partly fulfills the role of enabling the activities of the KF, as well as the SF the LL framework. As the numbers of the FB page grew and the collaboration efforts gained more and more momentum, a platform was needed for group members to be able to share resources with descriptions. The initial sorting and process was solely managed and maintained by the same educator who started the group and the classification process was a tedious one.

The description from the TechTeachers.co.za site is presented as "a web site where teachers of Computer Applications Technology, Information Technology and Computer Literacy in South Africa can have access to centralized resources, materials and assessments created by teachers and shared freely by teachers. There is also an online Facebook forum where teachers can discuss class ideas, projects, challenges and proposals. The site encompasses a national community of teachers of computer subjects." (TechTeachers.co.za, 2014). 


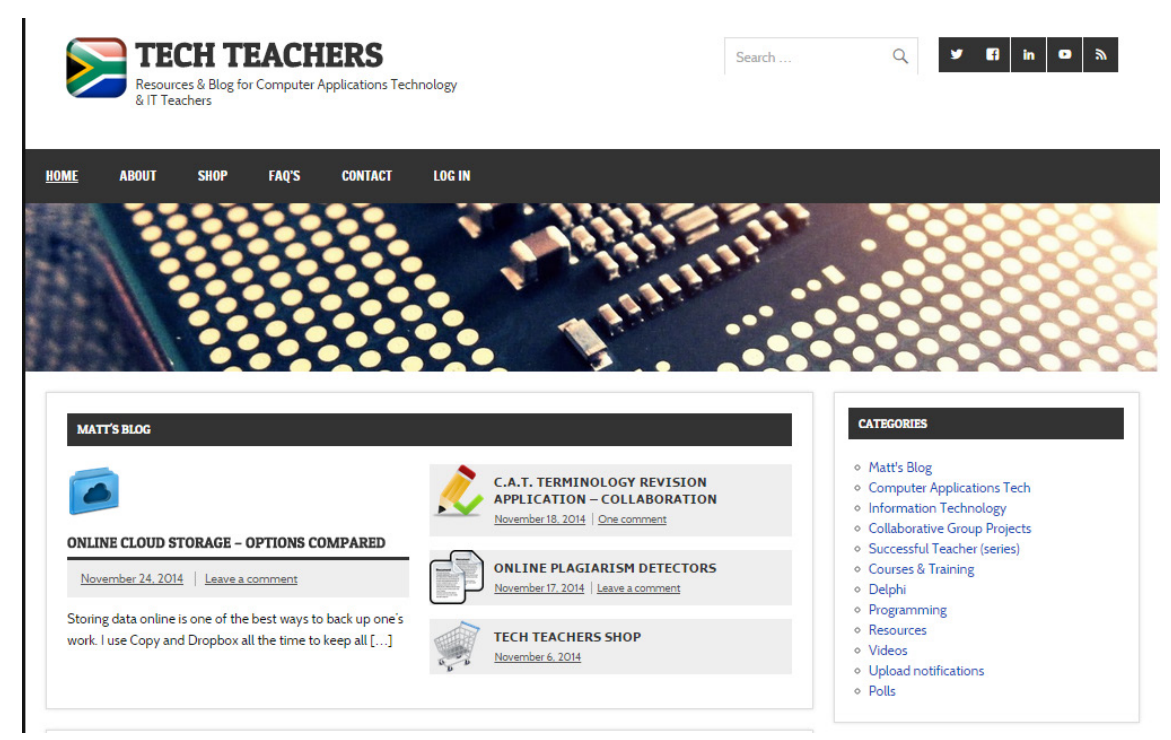

Figure 5: A screenshot from the TechTeachers blog

The purpose of the TechTeachers.co.za in conjunction with the FB page is presented as a common platform to:

- Pool and share resources with teachers from all over the country.

- Allow teachers to interact with each other.

- Provide a secure 'members-only' environment to share materials amongst professionals.

- Create, maintain and promote a community for teachers teaching Computer Application Technology and Information Technology.

- Assist with course development and teacher training.

- Engage with a national community of teachers.

As of February 2015 there are almost 800 registered members as part of the blog. Funding to host, maintain and keep the site running is obtained through advert banners and having members pay a small annual registration fee. The annual fee of R250.00, which equates to about 23US\$, is kept to the minimum and is normally paid by the schools or educational institutions that the educator or member belong to.

Payment is not compulsory and teachers who cannot afford to join or who cannot obtain the funds to join are accommodated accordingly. The registration fee also has a twofold purpose: one towards generating funds and the other as deterrent to individuals who may not belong to an educational community or learners. In order to motivate and encourage further member participation certain sections of the blog are presented as free resources.

The categories covered are for IT and CAT, and any general ICT related teachers. The content presented take on various forms, ranging from resources to the latest news in technology. The major aim of all content is help and facilitate teachers to be equipped with knowledge as to inspire their students and set an example. Various other teachers present content as part of YouTube, and these are shared in a category called "Tech-Time". 


\section{Testimonials and 'Living-Labbing' benefits}

The concept of 'living-labbing' relates to the active participation as a member of the CoP within a LL. Mulder, (2012) explains that "'living-labbing' allows facilitation, and on the other hand, it facilitates participation."

The growth and subsequent success of both of the web technologies are based on the fact that the reward for collaboration is shared by all. Some of the testimonials presented as part of the TechTeachers.co.za site from fellow members are presented next. These do not only highlight the use value but also the key concepts in the practice of "living-labbing", such as creating a sense of belonging, creating subject champions, and advancing the subjects as a whole.

"I love the collaboration that happens on this site and the friendly people that are part of it! Fantastic concept, great resources and lots of interesting reading."

"Our school does not offer IT and I'm the only CAT teacher. I find the Tech Teachers' website and Facebook page extremely helpful as I often feel isolated and out of my depth. The database of assessments is invaluable and I often have a question or comment which I know will be responded to timeously. You guys are my virtual 'colleagues' and I love being part of this group!"

"Our school does not offer IT and I'm the only CAT teacher. I find the Tech Teachers' website and Facebook page extremely helpful as I often feel isolated and out of my depth. The database of assessments is invaluable and I often have a question or comment which I know will be responded to timeously. You guys are my virtual 'colleagues' and I love being part of this group!"

"All I can say is WOW! This is an incredible site/resource for ALL teachers, teaching CAT now for 15 years (first the SG) and have never experienced a resource like this."

"Discovering the Facebook site and the support website has been life-changing. It has put me in touch with teachers who are experiencing the same frustrations (and joys). The support is amazing and has added such value to my life, as an educator. I am just sorry I did not get on board ages ago!"

From the testimonials as well as current user and member experiences the following intrinsic benefits of collaboration are evident:

- Work gets done faster. Creating resources for teachers takes a lot of time outside of normal work hours. Sharing resources, such as lesson plans and tutorials proven to work by others, allows a teacher to have more time to peruse other teaching and subject related matters.

- All parties benefit from the collective knowledge and resource base as multiple related knowledge and teaching resources become available.

- New members are introduced to other members and opportunities for networking within regional and district domains become a reality.

- The motto of 'Learn to grow, and grow to learn' becomes a reality which impacts not only the direct member community but also the indirect community such as all the learners involved.

- There is an increased standard of work that is driven by the practice of allowing other members to provide input and enhancements to all materials as well as an increased perception of presenting work by members that is of a high standard.

- An indirect learning opportunity is created when teachers need to interpret informal an unstructured teaching material created by peers.

- The overall ICT education value chain is improved as the end product is subsequently bettered. 


\section{Lessons Learned and Best Practices}

During the initial establishment and existence of the Facebook page and the subsequent establishment of the TechTeachers blog, various key lessons were learned, which could prove helpful best practices for similar endeavors. These lessons include operational issues and facts such as:

- Peer authentication plays an important role to ensure that members with the right intent join the group.

- The practice of participating in LL activities also creates opportunities to identify new areas of training such as developing courses to help teachers to be able to create their own blog's and lesson videos.

- Being able to assign a face to a person, as is the case with Facebook, allows for members to associate better and to recognize each other at cluster and other meetings, which is often not the case with mailing lists.

- Ensuring a professional culture amongst group members is enhanced by allowing members of the group to be part of the formation of the rules.

- A culture of sharing is greatly catalyzed through the realization of the available reward. The more members share and are able to see and realize the value of sharing the more members are willing to share.

- Encouraging members to partake in the collaborative development of assessments, tutorials, and videos allows for faster adaptations towards a successful product instead of waiting for comments at a later post implementation stage.

- The continuous content updates on the website and Facebook group creates community awareness leading to interest and engagement.

- Communication between teachers enables the ability for individuals in the community to measure themselves against peers.

- The frequent and regular sharing of content and materials encourages other teachers to share by establishing a sharing culture that values content without being overly critical.

- Intrinsic peer review mechanism provide an organic filter for copyrighted and plagiarized material as teacher participating in the community can easily identify such sources.

\section{Conclusion}

This paper gave a brief overview of the success story of two web based technologies and the modeling thereof as a Living Lab to provide the secondary ICT education sector with educational value. Relevance within a Living Lab as a representation of a larger environment can act as a test bed for new concepts, technologies, educational material, and teaching strategies.

A previous section of this article presented a LL framework modeled around the utilization and logical groupings of activities as part of factories. In its current form both the operations and the existing TechTeachers web sites do confirm to the framework presented. It is however the ultimate goal of the researchers to have the TechTeachers $\mathrm{CoP}$ registered as a full living lab with the network of living labs in South Africa (LLiSA) and to be part of the European Network of Living Labs (ENoLL). Having the TechTeachers LL established will create opportunities and provide a platform to:

- obtain national and international recognition from similar educational sectors and peers, with could kindle more collaboration efforts. 
- obtain funds to facilitate the hosting of and design of other services, and workshops voiding the need for a registration fee.

- create similar groups for other educational intensive subjects such as mathematics and science and technology related subjects.

- help realize the consequences of the GT study as presented in Figure 3

Further research results obtained by applying the LL framework to the current operations of the pseudo TechTeachers LL will be used as part of presentation towards the 9th Wave of membership application towards ENoLL.

We believe that a substantial amount of focus should be placed on the development and sharing of educational materials and tools to address the right issues in the right context and provide solutions and opportunities for growth and development. From the positive feedback received by all current members and their continued commitment, the researchers believe that the final LL has the potential to achieve the desired outcomes and to benefit the broader community.

\section{References}

Ausband, L. (2006). Qualitative research and quilting: Advice for novice researchers. Qualitative Report, 11(4), $764-770$.

Avellis, G., Agrimi, A., Di Ciano, M., Grasso, G., \& Surico, F. (2015). E-learning issues in education \& training domain of Apulian Living Labs. Journal of E-Learning and Knowledge Society, 11(1). Retrieved from http://www.je-lks.org/ojs/index.php/Je-LKS_EN/article/view/985

Brown, I., Gordon, C., Janik, N., \& Meyer, M. (2005). Investigating adoption/non-adoption of cell phones for financial transactions in South Africa. Proceedings of ACIS 2005. Retrieved from http://aisel.aisnet.org/acis2005/51/

Buitendag, A. A. K., Hattingh, F. G., \& Van der Walt, J. S. (2013). A framework for using questions as metatags to enable knowledge support services as part of a living lab environment. Issues in Informing Science and Information Technology, 10, 18-15.

Buitendag, A. A. K, Wassermann, U., \& Pretorius, C. M. (2013). Utilising living lab principles to model and create a collaborative education environment-The CAT schools programme. In IST-Africa Conference and Exhibition (IST-Africa), 2013 (pp. 1-11).

Cilliers, J. (2008). In search of meaning between Ubuntu and Into: Perspectives on preaching in post-apartheid South Africa. Paper delivered at the Eighth International Conference of Societas Homiletica, Copenhagen, Denmark. Retrieved from http://academic.sun.ac.za/tsv/Profiles/Profile_documents/Johan_Cilliers_IN_SEARCH_OF_MEANING_BE TWEEN_UBUNTU_AND_INTO.pdf

Comp-Studies. (2014). comp-studies -- Closed list for teachers of IT and CAT in Southern Africa. Retrieved February 20, 2014, from http://www.esn.org.za/mailman/listinfo/comp-studies

Creswell, J. W. (2012). Qualitative inquiry and research design: Choosing among five approaches. SAGE Publications.

Cunningham, P., Herselman, M., \& Cunningham, M. (2011). Supporting the evolution of sustainable living labs and living lab networks in Africa. IIMC International Information Management Corporation.

De Jager, R. (2011). Latest changes in the technology education curriculum in South Africa. In PATT 25:CRIPT8 Perspectives on Learning in Design \& Technology Education (pp. 144-151). London: Goldsmiths.

DoE - Department of Education South Africa (n.d.). Curriculum Assessment Policy Statements (CAPS). Department of basic education South Africa. Retrieved November 28, 2014, from http://www.education.gov.za/Curriculum/CurriculumAssessmentPolicyStatements/tabid/419/Default.aspx 
DoE - Department of Education South Africa. (2010a). Curriculum and Assessment Policy - CAT (Computer Applications Technology).

DoE - Department of Education South Africa. (2010b). Curriculum and Assessment Policy - IT (Information Technology).

European Network of Living Labs (ENoLL). (2012). European Living Lab Knowledge Centre. Retrieved February 15, 2012, from http://knowledgecenter.openlivinglabs.eu/

Esteves, J., Ramos, I., \& Carvalho, J. (2002). Use of grounded theory in information systems area: An exploratory analysis. In Proceedings of European Conference on Research Methodologies on Business Management (pp. 129-136).

Ford, M., \& Leinonen, T. (2009). MobilED - Mobile tools and services platform for formal and informal learning. In M. Ally (Ed.), Mobile learning: Transforming the delivery of education and training (pp. 195-214). Edmonton: AU Press.

Følstad, A. (2008). Living labs for innovation and development of information and communication technology: A literature review. The Electronic Journal for Virtual Organizations and Networks, 10, 99-131.

Glaser, B. G. (2007). All is data. The Grounded Theory Review, 6(2), 2-22.

Legotlo, M. W., Maaga, M. P., Sebego, M. G., van der Westhuizen, P. C., Mosoge, M. J., Nieuwoudt, H. D., \& Steyn, H. J. (2002). Perceptions of stakeholders on causes of poor performance in Grade 12 in a province in South Africa. South African Journal of Education, 22(2), 113-118.

Lucassen, I., Klievink, A. J., \& Tavasszy, L. A. (2014). A living lab framework: Facilitating the adoption of innovations in international information infrastructures. In Proceedings of Transport Research Arena 2014, Paris, France, 14-17 April 2014.

Mulder, I. (2012). Living labbing the Rotterdam way: Co-creation as an enabler for urban innovation. Technology Innovation Management Review, 2(9). Retrieved from http://timreview.ca/article/607

Neill, C. J. (n.d.). Systems thinking. Retrieved from http://personal.psu.edu/staff/c/j/cjn6/Personal/Systems.pdf

Ormrod, J. E., \& Leedy, P. D. (2005). Practical research: Planning and design. New Jersey: Pearson Education.

Pallot, M. (2009). The living lab approach: A user centred open innovation ecosystem. Webergence Blog. Retrieved from: http://www.cwe-projects.eu/pub/bscw.cgi/715404

Pallot, M. (2012). A holistic model of user experience. Webergence Blog. Retrieved May 2012 from http://www.cweprojects.eu/pub/bscw.cgi/715404

Pallot, M., Alishevskikh, A., Pawar, K., Ruland, R. \& Prinz, W. (2013). Connective experience: Co- creating a semantic enabled serendipity service for living labs and internet of things. In Proceedings of the IEEE International Technology Management Conference \& 19th International Conference on Engineering, Technology and Innovation, ICE.

Scott H. (2009). What is grounded theory? Retrieved from http://www.groundedtheoryonline.com/what-isgrounded-theory

Senge, P. M. (1990). The fifth discipline: The art and practice of the learning organization (p. 68). New York: Doubleday/Currency.

Serrat, O. (2008). Building communities of practice. Retrieved from http://digitalcommons.ilr.cornell.edu/intl/118/?utm_source=digitalcommons.ilr.cornell.edu $\% 2 \mathrm{Fintl} \% 2 \mathrm{~F} 118$ \&utm_medium=PDF\&utm_campaign=PDFCoverPages

TechTeachers.co.za (2014). TECH TEACHERS, Resources \& Blog for Computer Applications Technology \& IT Teachers. Retrieved from: http://techteachers.co.za/

Teferra, D., \& Altbachl, P. G. (2004). African higher education: Challenges for the 21 st century. Higher Education, 47(1), 21-50. 
Van der Walt, J. S., Buitendag, A. A., Zaaiman, J. J., \& Van Vuuren, J. J. (2009). Community living lab as a collaborative innovation environment. Issues in Informing Science and Information Technology, 6, 421-436.

Wenger, E. (2006). Communities of practice - A brief introduction. Retrieved from http://wengertrayner.com/theory/

Welch, T. (2002). Teacher education in South Africa before, during and after apartheid: An overview. In J. Adler \& Y. Reed (Eds.), Challenges of teacher development: An investigation of take-up in South Africa (pp. 1733). Pretoria: Van Schaik.

\section{Biographies}

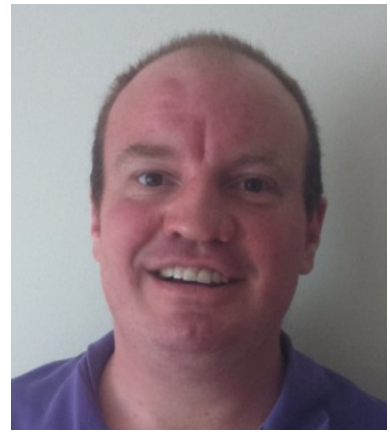

Bertie Buitendag is currently enrolled for his D-Tech in Enterprise Application Development at TUT under the supervision of Prof JS van der Walt. His core research area includes ICT Knowledge support for emergent farmers and Living Labs. Other areas of interest include the: Semantic Web, (WEB 3.0) and WEB 2.0, and ICT's for community upliftment.

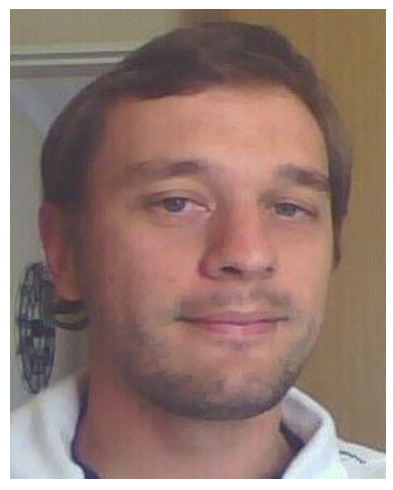

Fredre Hattingh is currently enrolled for his M-Tech in Technical Applications at TUT. His research interests include Living Labs, Virtualization and Plagiarism detection. Other areas of interests include Open Source Software and emerging technologies.

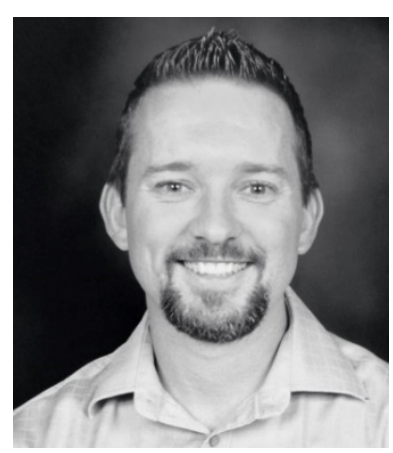

Matthew Hains is a Computer Applications Technology and Information Technology teacher for Grade 10 to Grade 12 at Woodlands International College in Boksburg, Gauteng, South Africa. He qualified as a teacher in 1997 and spent a lot of time getting involved in training teachers, students and corporate clients on the use of computer technology. After spending time in the UK as an IT administrator he returned to South Africa to continue teaching and is actively involved in technology education both locally at the school and online across the country with a network of computer technology teachers. Matt is the orchastrator and administrator of the both TechTeachers blog and equivalent facebook page. 